\title{
Impact of a Heat Shock Protein Impurity on the Immunogenicity of Biotherapeutic Monoclonal Antibodies
}

\author{
Shraddha S. Rane' - Rebecca J. Dearman ' Ian Kimber' - Shahid Uddin ${ }^{2} \cdot$ Stephen Bishop ${ }^{3}$. \\ Maryam Shah' • Adrian Podmore ${ }^{2}$ • Alain Pluen ' • Jeremy P. Derrick' (1)
}

Received: 2 November 2018 / Accepted: 5 February 2019 / Published online: 15 February 2019

(C) The Author(s) 2019

\begin{abstract}
Purpose Anti-drug antibodies can impair the efficacy of therapeutic proteins and, in some circumstances, induce adverse health effects. Immunogenicity can be promoted by aggregation; here we examined the ability of recombinant mouse heat shock protein 70 (rmHSP70) - a common host cell impurity to modulate the immune responses to aggregates of two therapeutic mAbs in mice.
\end{abstract}

Methods Heat and shaking stress methods were used to generate aggregates in the sub-micron size range from two human $\mathrm{mAbs}$, and immunogenicity assessed by intraperitoneal exposure in $\mathrm{BALB} / \mathrm{c}$ mice.

Results rmHSP70 was shown to bind preferentially to aggregates of both mAbs, but not to the native, monomeric proteins. Aggregates supplemented with $0.1 \%$ rmHSP70 induced significantly enhanced IgG2a antibody responses compared with aggregates alone but the effect was not observed for monomeric mAbs. Dendritic cells pulsed with $\mathrm{mAb}$ aggregate showed enhanced IFN $\gamma$ production on co-culture with T cells in the presence of rmHSP70.

Conclusion The results indicate a Th1-skewing of the immune response by aggregates and show that murine rmHSP70 selectively modulates the immune response to $\mathrm{mAb}$ aggregates, but not monomer. These data suggest that

Electronic supplementary material The online version of this article (https://doi.org// 0. 1007/s I 1095-019-2586-7) contains supplementary material, which is available to authorized users.

Jeremy P. Derrick

Jeremy.Derrick@manchester.ac.uk

School of Biological Sciences, Faculty of Biology Medicine and Health

Manchester Academic Health Science Centre, The University of

Manchester, Michael Smith Building

Oxford Road, Manchester MI3 9PT, UK

2 Medimmune Ltd, Granta Park, Cambridge CB2I 6GH, UK

3 Medimmune, I Medimmune way, Gaithersburg, Maryland 20878, USA heat shock protein impurities can selectively accumulate by binding to $\mathrm{mAb}$ aggregates and thus influence immunogenic responses to therapeutic proteins.

KEY WORDS adaptive immunity · aggregation · host cell impurity · immunogenicity · monoclonal antibody

$\begin{array}{ll}\text { ABBREVIATIONS } \\ \text { ADA } & \text { Anti-drug antibody } \\ \text { AF }^{4} & \text { Asymmetric flow field flow fractionation } \\ \text { APCs } & \text { Antigen presenting cells } \\ \text { BMDC } & \text { Bone marrow-derived dendritic cells } \\ \text { BSA } & \text { Bovine serum albumin } \\ \text { CHO } & \text { Chinese hamster ovary } \\ \text { DLS } & \text { Dynamic light scattering } \\ \text { HCP } & \text { Host cell protein } \\ \text { HRP } & \text { Horseradish peroxidase } \\ \text { IFNß-Ia } & \text { Interferon beta-la } \\ \text { I.P. } & \text { Intraperitoneal } \\ \text { mAb } & \text { Monoclonal antibody } \\ \text { NMS } & \text { Normal mouse serum } \\ \text { PBS } & \text { Phosphate buffered saline } \\ \text { RICS } & \text { Raster image correlation spectroscopy } \\ \text { rmHSP70 } & \text { Recombinant mouse heat shock protein } 70 \\ \text { ROI } & \text { Region of interest } \\ \text { scFv } & \text { Single chain variable fragment }\end{array}$

\section{INTRODUCTION}

Monoclonal antibodies (mAbs) are the fastest growing sector of the global pharmaceutical industry, particularly for the treatment of cancer and inflammatory diseases [1,2]. Unwanted immunogenicity and the formation of anti-drug antibodies (ADAs) is a significant challenge for the use of biotherapeutics, even for those that have been humanized 
[3], impacting safety and efficacy. A variety of factors can influence immunogenicity: these include product-related factors such as protein conformation or impurities, patientrelated variables such as immune and genetic background, disease status and treatment-related factors such as route and duration of exposure $[4,5]$. Aggregation is an important factor which has been implicated in immunogenicity and its likelihood is increased with the use of mAbs at high concentrations [6-8]. The link between aggregation and enhanced immunogenic responses is well established in mouse models (including transgenic animals). For example, aggregate percentage and the extent of denaturation of interferon beta-la (IFN $\beta$-1a) have been shown to influence the ability of aggregates to break tolerance in transgenic mice [9]. Only aggregates that retained native epitopes were able to stimulate a transient immune response and their removal prevented the breakdown of tolerance [9]. Aggregation is thought to be initiated by association of partially unfolded conformational states which can occur at any stage of bioprocessing and storage. They range in size and dimensions in the 0.1-10 $\mu \mathrm{m}$ range have been identified as being the most immunogenic [10]. Characteristics of aggregates which may contribute to immunogenic potential include the formation of neo-epitopes, multiple valency, post-translational modifications, concentration and size [11-13]. Despite the wealth of evidence demonstrating that aggregation results in enhanced immunogenicity, the underlying mechanisms are incompletely understood [14].

The removal of host cell protein (HCP) impurities is an important problem in the isolation of biologics for clinical use [15]. HCPs originate from the expression host, most commonly Chinese Hamster Ovary (CHO) cells for monoclonal antibodies. Measurement of total HCP content is commonly conducted by ELISA: null cell line isolates are used to immunize mice and obtain polyclonal antisera. This method is limited, however, in that it is dependent on the total average response to a crude mixture of HCPs which will, individually, have differential abilities to stimulate antibody production [15]. HCPs have been shown to influence immunogenicity as antigens or adjuvants [16,17], through HCP-induced protease activity [18] or direct biological activity [17], highlighting the need for HCP identification and individual quantification.

Heat shock proteins (HSPs) are a common HCP impurity [19]; they participate in housekeeping functions and are part of responses to environmental stresses [20,21]. Their chaperone activity in macromolecular complex assembly, protein transport and degradation acts to stabilize and correct the folding of nascent polypeptides de novo, dissociating aggregates, and re-folding stress-denatured proteins [22]. Stresses can exacerbate protein conformational problems, exceeding the capacity of chaperone systems to prevent aggregation. In addition, the combined use of HSPs has been explored as a strategy for enhancing vaccine potency [23]. Studies have shown, for example, that HSP-peptide complexes successfully elicited MHG class I restricted cytotoxic T lymphocyte responses, whereas HSP or peptide alone were not immunogenic, establishing the tumor-derived HSP gp96 as the first adjuvant of mammalian origin [24]. HSP-based cancer vaccines, such as artificially reconstituted HSP peptide antigen complexes, have been widely exploited [25]. In addition, the adjuvant property of mycobacterial Heat Shock Protein 70 fusion protein has been demonstrated using a variety of model antigens [26]. Our laboratory has recently shown that low levels of an E. coli HSP, DnaK, were able to enhance the immunogenicity of a recombinant $25 \mathrm{kDa}$ human single chain variable fragment ( $\mathrm{scFv}$ ) following immunization of $\mathrm{BALB} / \mathrm{c}$ strain mice [27]. HSPs therefore have the potential to function as adjuvants.

The principal aim of the current investigation was to establish whether this adjuvant-like effect could also be observed with aggregated human biotherapeutic mAbs and a cognate mammalian HSP, similar to that found in CHO cells. To this end, we used recombinant mouse HSP70 (rmHSP70), an ortholog of $E$. coli DnaK which is $98 \%$ identical to $\mathrm{CHO}$ HSP70 [27]. We show that rmHSP70 binds preferentially to aggregates and is able to exert an adjuvant-like effect on immune responses in a BALB/c mouse model. The implications for the contribution of HCPs to the immunogenicity of therapeutic protein aggregates are discussed.

\section{MATERIALS AND METHODS}

\section{Animals}

Female BALB/c strain mice (8-12 weeks old) were used for these experiments (Envigo, Bicester, UK). Mice were housed on sterilized wood bedding with materials provided for environmental enrichment. Food (Beekay Rat and Mouse Diet Nol pellets; B\&K Universal, Hull, UK) and water were available ad libitum. The ambient temperature was maintained at $21 \pm 2^{\circ} \mathrm{C}$ and relative humidity was $55 \pm 10 \%$ with a $12 \mathrm{~h}$ light/dark cycle. All procedures were carried out in accordance with the Animals (Scientific Procedures) Act 1986, and approved by Home Office licence.

\section{Monoclonal Antibodies}

Two human monoclonal antibodies were used for the current study, hereafter referred to as $\mathrm{mAb} 1$ and $\mathrm{mAb} 2$. mAb1 has a theoretical molecular mass of $148 \mathrm{kDa}$ and an experimentally measured $\mathrm{p} I$ of 7.6. mAb2 (a bispecific antibody) has a theoretical molecular mass of $204 \mathrm{kDa}$ and an experimentally measured $\mathrm{p} I$ of 9.1 . Both the mAbs were provided by MedImmune (Cambridge, UK). 


\section{Aggregate Formation and Spiking with rmHSP70}

Purified mAbs were diluted into $1 \mathrm{mg} / \mathrm{mL}$ in Dulbecco's phosphate buffered saline (DPBS) without $\mathrm{Ca}^{+2}$ or $\mathrm{Mg}^{+2}$ (Sigma-Aldrich, St Louis, Missouri). In order to form aggregates of $\mathrm{mAbl}$ by thermal stress, it was treated at $60^{\circ} \mathrm{C}$ for $25 \mathrm{~min}$. To generate mAbl aggregates using shaking stress, the solution at $1 \mathrm{mg} / \mathrm{mL}$ was shaken in a bench top shaker at $3000 \mathrm{rpm}$ for $12 \mathrm{~h}$ at $22^{\circ} \mathrm{C}$. mAb2 aggregates were formed by shaking stress in the same way, but at $1500 \mathrm{rpm}$ for $4 \mathrm{~h}$ at $22^{\circ} \mathrm{C}$. rmHSP70-aggregate complex samples were prepared by addition of rmHSP70 (Enzo Life Sciences, UK) to $0.1 \%$ by mass into the $\mathrm{mAb}$ aggregate within $5 \mathrm{~min}$ of $\mathrm{mAb}$ aggregation. The aggregates formed were stable and did not dissociate into monomers when the temperature was subsequently decreased by refrigeration, or after storage at $-80^{\circ} \mathrm{C}$.

\section{Dynamic Light Scattering (DLS)}

Measurements of DLS were performed using a Malvern Zetasizer Nano ZS ZEN3600 (Malvern, Herrenberg, Germany), equipped with a $633 \mathrm{~nm}$ laser. Each sample $(70 \mu \mathrm{L})$ was measured in a Suprasil ${ }^{\circledR}$ quartz cuvette (Hellma $\mathrm{GmbH}$, Muellheim, Germany) with a path length of $3 \mathrm{~mm}$ and 200-2500 nm spectral range. Monomeric and stressed samples at $1 \mathrm{mg} / \mathrm{mL}$ were measured at $25^{\circ} \mathrm{C}$ to determine the volume-based average protein particle diameter in solution.

\section{Raster Image Correlation Spectroscopy (RICS)}

SYPRO ${ }^{\circledR}$ Red (Molecular Probes, Oregon) was prepared as a 50x stock solution in pre-filtered histidine-sucrose buffer and diluted to a final working concentration of $2.5 \mathrm{x}$ for fluorescence studies immediately prior to use (all solutions were prepared on the day of use) [28]. SYPRO ${ }^{\circledR}$ Red was added 15 min prior to visualization with confocal microscopy. A Zeiss 510 Confocor 2 (Zeiss, Jena, Germany) confocal microscope equipped with a c-Apochromat $40 \times / 1.2 \mathrm{NA}$ waterimmersion objective was used for image acquisition. Imaging was carried out by exciting the dye with a Helium-Neon laser at $543 \mathrm{~nm}$ and the emitted fluorescence collected above $585 \mathrm{~nm}$ (LP585 filter set). A confocal image time series of $1024 \times 1024$ pixel resolution was captured over 100 frames with a corresponding pixel dwell time of $6.4 \mu \mathrm{s}$. In-house RICS software (ManICS) was applied to analysis of images acquired using confocal microscopy. A full description of the RICS algorithm has been described elsewhere $[28,29]$. The image time series were sub-divided into $32 \times 32$ pixel subregions and the diffusion coefficients $(\mathrm{D})$ of each region of interest (ROI) was generated. The method is described in greater detail previously [28].
Asymmetric Flow Field Flow Fractionation $\left(\mathrm{AF}^{4}\right)$

Asymmetric flow field-flow fractionation $\left(\mathrm{AF}^{4}\right)$ is used to measure aggregate content and molecular mass distribution, as an orthogonal method to size exclusion chromatography or analytical ultracentrifugation. In the current study, aggregates of mAbl (generated by thermal stress) and mAb2 (generated by shaking stress) in the presence and absence of rnHSP70 were prepared as described above. Separation was achieved by a liquid cross-flow which takes place in a narrow, ribbonlike channel of trapezoidal geometry, which is built up by a spacer, between a porous and a nonporous plate. The porous plate is covered by a membrane, which acts as accumulation wall and allows the eluent to pass the membrane, while the particles/macromolecules are retained [30]. Water was used as solvent for the method at $25^{\circ} \mathrm{C}$, with 30 min analysis time and $0.294 \mathrm{~s}$ sampling time. The total area of the peaks and the molecular mass of the rmHSP70-aggregates were measured. Corresponding monomer mAbs (with and without rmHSP70) were used for comparison. The ASTRA chromatography software (Wyatt Technology) was used to analyse the data.

\section{Fluorescence Microscopy}

rmHSP70 (low endotoxin) was purchased and was obtained commercially labelled with BODIPY FL by Life Technologies, USA. BODIPY FL labelled rmHSP70 $(0.1 \%)$ was added to the thermal stressed $\mathrm{mAbl}$ and shaking stressed mAb2 aggregates. 2.5x SYPRO ${ }^{\circledR}$ Red dye was added to the aggregated $\mathrm{mAb}$ immediately before analyzing the sample using a Zeiss 510 Confocor 2 microscope.

\section{SDS Page}

Protein samples were diluted in SDS-PAGE sample buffer (Bio-Rad, Berkley, CA, USA) containing 1\%(v/v) 2mercaptoethanol and heated for $5 \mathrm{~min}$ at $90^{\circ} \mathrm{C}$. Samples were resolved on a pre-cast NuPAGE 4-12\% Bis-Tris Protein gels (Invitrogen ${ }^{\mathrm{TM}}$ ) and stained using InstantBlue ${ }^{\mathrm{TM}}$ Coomassie protein stain (Expedeon, Swavesey, UK).

\section{Western Blot}

Protein samples were resolved on pre-cast 4-12\% acrylamide gel at various concentrations $(0.1,0.01,0.001,0.005$ and $0.05 \mu \mathrm{g} / \mathrm{mL}$ in PBS), transferred onto nitrocellulose membrane and detected using anti-HSP70 horseradish peroxidase (HRP) conjugated antibody (StressMarq Bioscience Inc., Victoria, British Columbia, Canada) diluted at 1:2000. Proteins on the blots were visualized using enhanced chemiluminescence reagents (Thermo Scientific).

Monomer and aggregate samples were prepared as described previously. rmHSP70 was added at 1:1000 ratio by 
mass to monomer and aggregated mAbs. For monomeric samples, where pellets were not observed, $30 \mu \mathrm{l}$ PBS was added to the tube to dissolve any sedimented material. Protein samples were resolved on a pre-cast $4-12 \%$ acrylamide gel and transferred onto a nitrocellulose membrane. The presence of rmHSP70 was detected using anti-HSP70 horseradish peroxidase (HRP) conjugated antibody and blots were visualized using enhanced chemiluminescence reagents, as described above.

\section{Immunizations}

Mice ( $n=3$ or 5 per group) were immunized by intraperitoneal (I.P.) injection on days 0, 7 and 14 and were exsanguinated on day 21. Animals were immunized with $250 \mu \mathrm{L}$ of $1 \mathrm{mg} / \mathrm{mL}$ of $\mathrm{mAbl}$ and $150 \mu \mathrm{L}$ of $1 \mathrm{mg} / \mathrm{mL}$ of mAb2 (monomeric or aggregated) in PBS with or without rmHSP70 at a ratio of 1 in $1000(0.1 \%$ by mass) relative to the immunizing $\mathrm{mAb}$ immediately after aggregate formation. Individual serum samples were prepared and stored at $-80^{\circ} \mathrm{C}$ until analysis.

\section{ELISA for Analysis of Serum from mAb Immunized Mice}

To analyse the serum from mAb immunized mice, plastic Maxisorb® plates (Nunc, Copenhagen, Denmark) were coated with $0.1 \mathrm{mg} / \mathrm{mL}$ monomer or $0.05 \mathrm{mg} / \mathrm{mL}$ aggregate $\mathrm{mAbs}$ in PBS overnight at $4^{\circ} \mathrm{C}$. Protein-coated plates were blocked with $2 \%(w / v)$ bovine serum albumin (BSA)/PBS (Sigma Aldrich) at $37^{\circ} \mathrm{C}$ for $30 \mathrm{~min}$. Doubling dilutions of serum samples were added (starting dilution 1:140 for IgG, 1:1120 for IgG1, 1:35 for IgG2a and 1:70 for IgM) prepared in $1 \% \mathrm{BSA} / \mathrm{PBS}$ and plates incubated for $3 \mathrm{~h}$ at $4^{\circ} \mathrm{C}$. Negative control naïve mouse serum (NMS) or PBS sham control mouse serum samples were analyzed concurrently. Plates were incubated for $2 \mathrm{~h}$ at $4^{\circ} \mathrm{C}$ with HRP labelled sheep anti-mouse IgG diluted 1:4000, sheep anti-mouse IgG1 diluted 1:2000 (both Bio-Rad) or goat anti-mouse IgM diluted 1: 6000 (Invitrogen, Paisley, UK), diluted in 1\% BSA/ PBS. For IgG2a ELISAs, MCA1588P rat anti mouse IgG2a HRPheavy chain antibody (Bio-Rad) was used for mAbl and STAR133P goat anti mouse IgG2a HRP antibody (BioRad) was used for mAb2 (both at 1:1000 dilution). Plates were washed between incubations with $0.05 \%$ Tween 20 in PBS. For color development, plates were incubated with substrate $(1.6 \mathrm{mg} / \mathrm{mL}$ o-phenylenediamine and $0.4 \mathrm{mg} / \mathrm{mL}$ urea hydrogen peroxide in $0.5 \mathrm{M}$ citrate phosphate buffer ( $\mathrm{pH} 5)$ ), $100 \mu \mathrm{L} /$ well, for $15 \mathrm{~min}$ in the dark and reactions were stopped with $50 \mu \mathrm{L} /$ well of $0.5 \mathrm{M}$ citric acid. Absorbance was read at $450 \mathrm{~nm}$ using an automated reader (ELx800; BioTek Instruments, Inc., Winooski, US), using the Gen 5 1.10 software. Data are displayed with respect to antibody titre $\left(\log _{2}\right)$ calculated as the lowest serum dilution at which a 3x serum blank OD450nm reading was reached.

\section{$\left[{ }^{3} \mathrm{H}\right]$ Thymidine Splenocyte Proliferation Assay}

A single cell suspension of splenocytes from immunized mice was prepared using mechanical disaggregation. Splenocytes were stimulated in vitro with respective protein samples for 7 days. $5 \times 10^{4}$ cells/well splenocytes were co-cultured with $5 \times 10^{3}$ bone marrow derived dendritic cells (BMDCs) pulsed with the protein immunogen or no protein (for control) in quadruplicate in round-bottom 96-well plates [31]. $\left[{ }^{3} \mathrm{H}\right]$ thymidine incorporation proliferation assay method is described elsewhere [14]. Cultures were incubated for approximately $60 \mathrm{~h}$ at $37^{\circ} \mathrm{C}, 5 \% \mathrm{CO}_{2}$ and $\left[{ }^{3} \mathrm{H}\right]$ thymidine $\left({ }^{3} \mathrm{HTdR}\right)$ (PerkinElmer, Waltham, MA, USA) was added at $37 \mathrm{kBq} /$ well for the final $18 \mathrm{~h}$, plates were harvested onto glass fibre filter mats with a multichannel semi-automated harvesting device (Titertek, Skatron AS, Lierbyen, Norway) and quantified with $\beta$ scintillation counting. Results are presented as counts per min (cpm) as means of quadruplicates as described previously [31].

\section{Measurement of IFNy Secretion Using ELISpot Assay}

Splenocytes from immunized mice were cultured ex vivo using mAbl or mAb2. BMDCs prepared as described previously were used as Antigen Presenting Cells (APCs) [31]. ELISpot assays were performed according to the manufacturer's protocol (Mabtec, Nacka Strand, Sweden). Aliquots of $5 \times 10^{4}$ cells/well were assayed in triplicate. The plates were developed after $48 \mathrm{~h}$ with BCIP (5-bromo-4-chloro-3-indoyl phosphate p-toluidine salt) and NBT (p-nitro blue tetrazolium chloride) color development solution (Bio-Rad) for 30-45 min and plates were rinsed with tap water. Spots were quantitated with an ELISpot reader (Cellular Technology Limited, Bonn, Germany). An animal was scored as positive when the response in the peptide-containing well was at least twice that of control wells, as described previously [32].

\section{STATISTICAL ANALYSES}

Statistical analyses were performed using Graphpad Prism 7. Analysis of variance (ANOVA) was used to determine statistical significance of differences between groups. Experiments were analyzed by non-parametric one way or two way ANOVA followed by Tukey's post hoc test $(* p<0.05$, $* * p<0.01, * * * p<0.001)$. 


\section{RESULTS}

\section{Characterization of Therapeutic mAbs in Native and Aggregated States}

This investigation sought to investigate whether the adjuvant-like effect, observed previously using bacterial DnaK with aggregates of a scFv fragment [27], could also be recorded using intact monoclonal antibodies and a mammalian HCP. Consequently, two human IgG1 $\mathrm{mAbs}, \mathrm{mAb} 1$ and $\mathrm{mAb} 2$, were used in the current study. Both mAbs were prepared at $1 \mathrm{mg} / \mathrm{mL}$ in PBS and aggregates generated by application of thermal or shaking stress. $\mathrm{mAb} 2$ showed no aggregation in response to thermal stress (at 45,50 or $60^{\circ} \mathrm{C}$ ) but aggregates of $\mathrm{mAbl}$ were generated by both methods. The sizes of the generated $\mathrm{mAbl}$ and mAb2 aggregates were analyzed by DLS (Fig. 1a). Both $\mathrm{mAb}$ monomers showed a narrow size distribution at $\sim 10 \mathrm{~nm}$, as anticipated (dashed line). Application of thermal stress to $\mathrm{mAbl}$ generated an aggregate population within the sub-visible size range. Aggregate sizes were much larger $(\sim 1 \mu \mathrm{m})$ when formed by shaking stress for both mAb1 and mAb2 (Fig. 1a, solid line). For mAb1, different stress conditions (thermal stress, shaking stress, and stir stress) were found to give rise to different size populations of aggregate species, as analysed by DLS (Supplementary Fig. 1A). The mAb1 and mAb2 aggregates generated were irreversible and did not dissociate on dilution. In contrast to $\mathrm{mAb} 1, \mathrm{mAb} 2$ appeared more stable to different stresses applied and demonstrated different aggregation kinetics. Agitation stress was also applied to both mAbs using a tube rotator for up to $24 \mathrm{~h}$, but failed to generate detectable aggregates (Supplementary Fig. 1). To characterize the aggregate populations more comprehensively, they were analyzed by Raster Image Correlation Spectroscopy (RICS). RICS provided a quantitative measurement of aggregate numbers (particles/fL) for four different size ranges, and for both mAbs (Fig. 1b). The results confirm that shaking stress caused aggregates to form within the $0.05-0.5 \mu \mathrm{m}$ and $0.5-5 \mu \mathrm{m}$ size ranges, a shift to larger size populations compared with the results of thermal stress induction on mAbl. These aggregate preparations were then used for an analysis of murine recombinant HSP70 (rmHSP70) binding and immunological responses. a

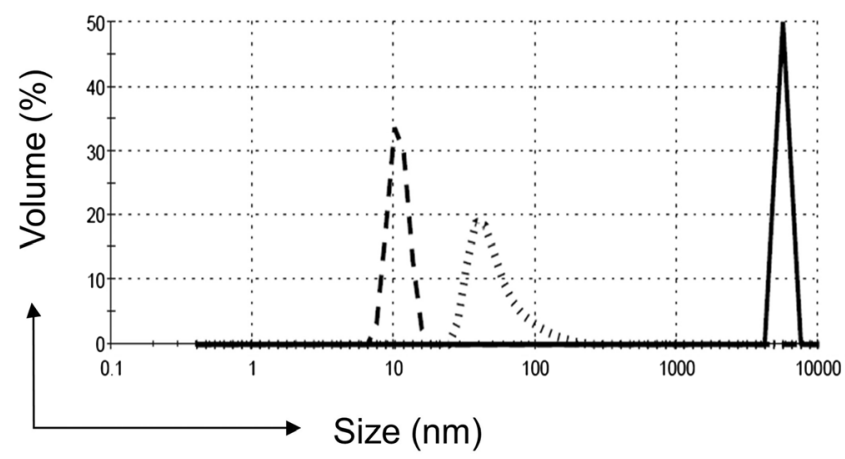

b

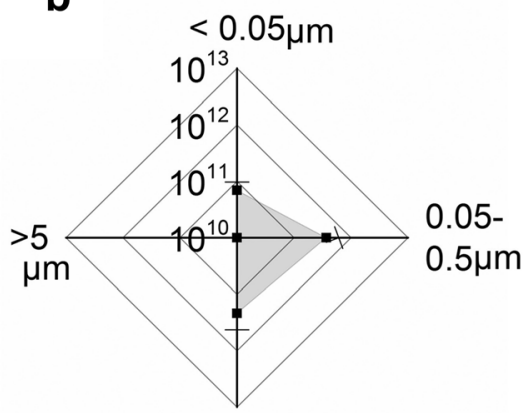

$0.5-5 \mu \mathrm{m}$

$m A b 1$

thermal stress induced aggregate

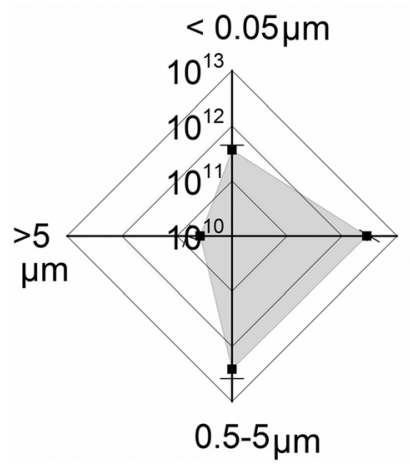

mAb1
mAb2

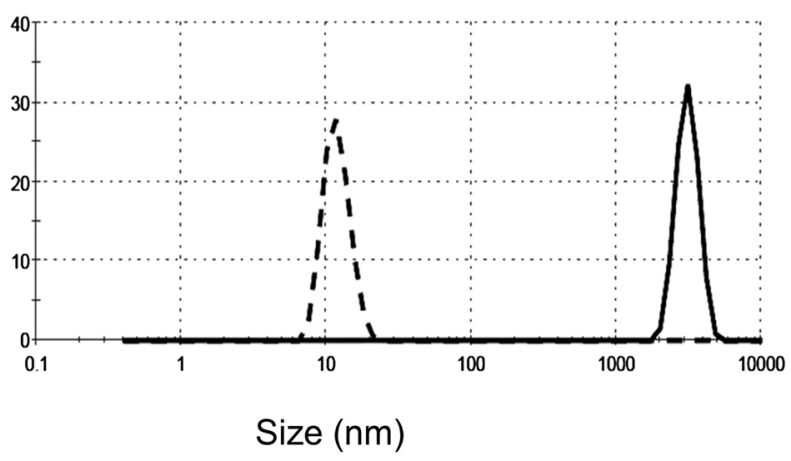

Fig. I Characterization of mAb I and mAb2 aggregates by DLS and RICS. (a) Aggregate particle size measured using DLS. Dashed line, monomer mAb; solid line, shaking stress induced aggregated mAb; dotted line, thermal stress induced aggregated mAb. (b) Analysis of aggregate species using RICS. Horizontal and vertical axes represent particle counts per $\mathrm{mL}$. Data were separated into size ranges of $<0.05,0.05-0.5,0.5-5$ and $>5 \mu \mathrm{m}$. Values represent means $\pm \mathrm{SD}(n=3)$. 


\section{Binding of rmHSP70 to mAbI and mAb2 Aggregates}

Our previous work has shown that the HSP DnaK was able to bind to $\mathrm{scFv}_{\mathrm{V}}$ aggregates, a property which could contribute to its stimulation of immune response to aggregates [27]. We therefore conducted similar experiments to examine whether rmHSP70 was able to bind to aggregates of mAbl and mAb2. rmHSP70 was added at $0.1 \%$ by mass with respect to $\mathrm{mAb}$ concentration to monomer or aggregated mAbl and $\mathrm{mAb2}$, insoluble aggregates were separated from monomer by centrifugation, and supernatant and pellet fractions were analyzed by western blotting using anti-rmHSP70 antibody (Fig. 2; SDS PAGE gel images are shown in Supplementary Fig. 2a and b). The partition of rmHSP70 was compared in the presence of monomeric mAb (right panels of Fig. 2a, b) or aggregated mAb (left panels of Fig. 2a, b). rmHSP70 alone migrated as a monomer $(\sim 75 \mathrm{kDa})$ or dimer $(\sim 150 \mathrm{kDa})$. For both $\mathrm{mAbl}$ and $\mathrm{mAb} 2$, rmHSP70 selectively accumulated into the aggregated pellet fractions; this was not the case for monomeric $\mathrm{mAb1}$ and $\mathrm{mAb} 2$, where rmHSP70 was exclusively found in the supernatant. We conclude that rmHSP70 selectively binds to $\mathrm{mAb} 1$ or mAb2 aggregates, rather than monomer.

Asymmetric Flow Field Flow Fractionation $\left(\mathrm{AF}^{4}\right)$ was used as an additional method to examine rmHSP70 binding to the aggregated $\mathrm{mAb}$ preparations. Migration profiles of $\mathrm{mAbl}$ and mAb2 monomers and aggregates were compared with a

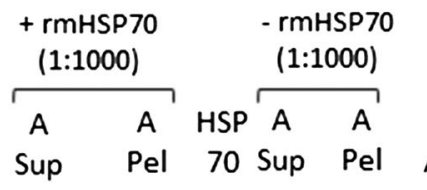

\section{mAb1}

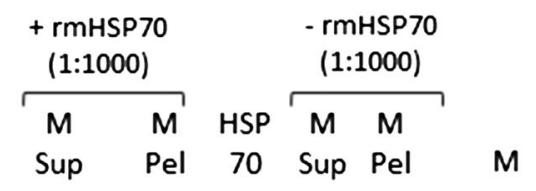

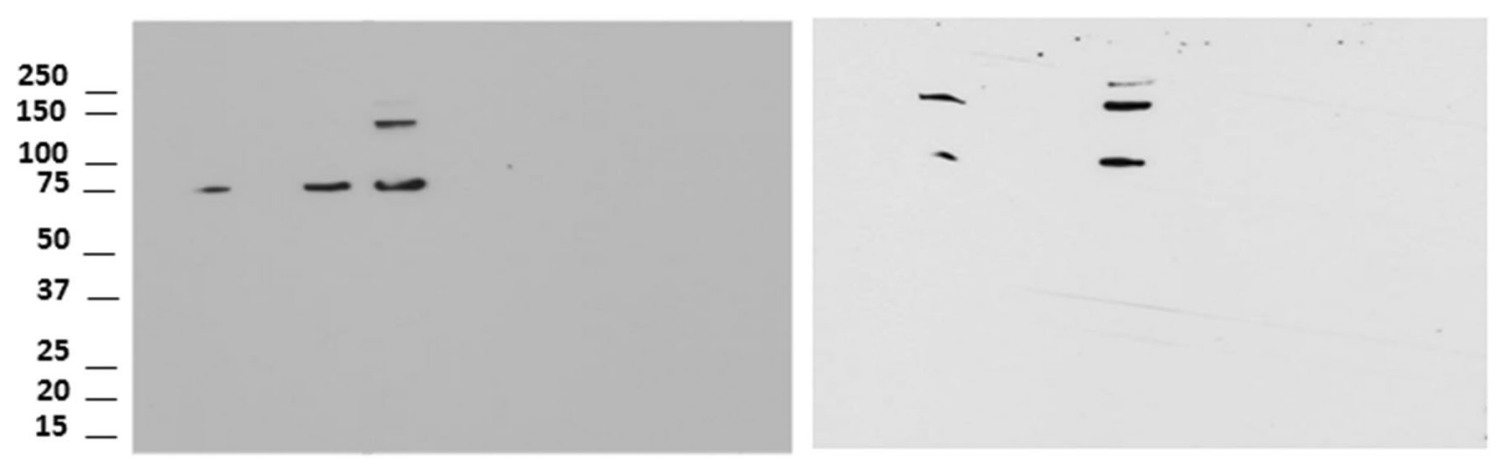

mAb2

b

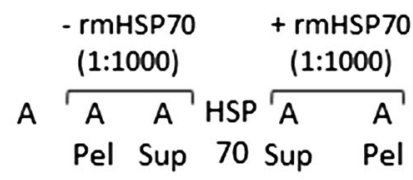

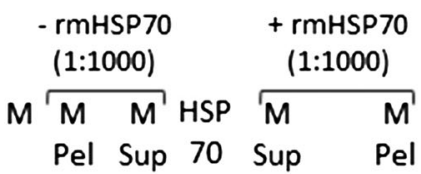

\begin{tabular}{llll}
$(1: 1000)$ & \multicolumn{2}{c}{$(1: 1000)$} \\
\cline { 3 - 4 } & $\begin{array}{lll}\text { M M HSP } \\
\text { Pel Sup 70 }\end{array}$ & Sup & Pel
\end{tabular}
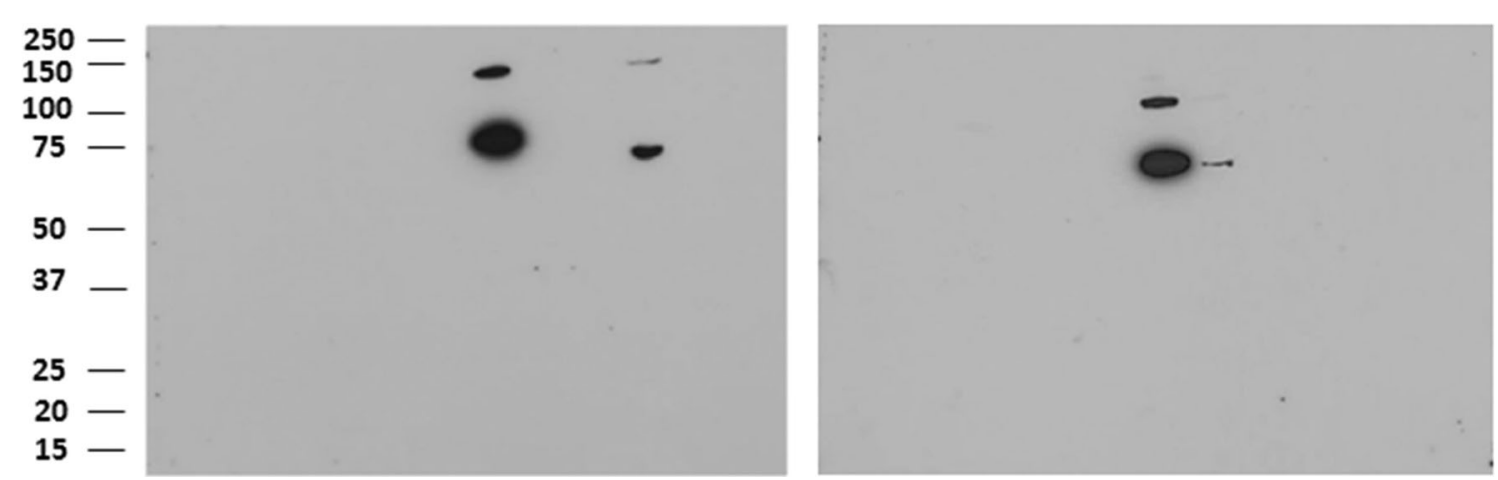

Fig. 2 Partition of rmHSP between aggregated and monomer fractions analyzed using western blot. $\mathrm{mAb} / \mathrm{and} \mathrm{mAb} 2 \mathrm{were} a g g r e g a t e d ~ u s i n g$ thermal and shaking stresses, respectively. rmHSP70 was added at 0.1\% by mass to monomer and aggregated mAbs immediately after aggregation. Samples were centrifuged at 12000 rpm for 30 min to sediment aggregated species; pellet and supernatants were then harvested. Blots were incubated with HRP conjugated anti rmHSP70 antibody and developed by chemiluminescence. Lanes are labelled as follows, M, monomer; A, aggregate; Sup, supernatant; Pel, pellet. 
and without rmHSP70 addition (Fig. 3). $50 \mu \mathrm{L}$ of mAb1 and $10 \mu \mathrm{L}$ of mAb2 samples were loaded to obtain optimum elution profiles; the heights, peak areas and elution times are shown in Table I. Addition of rmHSP70 did not significantly alter the elution times of monomers or aggregates but increased the peak area, by $22 \%$ for mAbl aggregate and, remarkably, about $300 \%$ for mAb2 aggregate (Table I). No such effects were seen for addition of rmHSP70 to $\mathrm{mAb}$ monomers. We propose that these effects are caused by changes to aggregate properties, such as shape, rather than overall mass, and therefore indirectly influence peak area. This is understandable, given that rmHSP70 was only added to $0.1 \%$ of $\mathrm{mAb}$ content by mass. A summary of each run with the peaks for $\mathrm{mAb} 1$ and $\mathrm{mAb} 2$ monomer and aggregated proteins (with/without rmHSP70) are shown in Supplementary Fig. 3. The results provide additional support for the specific interaction of rmHSP70 with mAb aggregates.

The effect of rmHSP70 on the $\mathrm{AF}^{4} \mathrm{mAb}$ aggregate profiles prompted us to investigate the interaction further by microscopy. rmHSP70 was labelled with the green fluorescence dye BODIPY and its binding to mAbl and mAb2 aggregates studied. SYPRO® Red dye was added to mAb1 and mAb2 aggregates which were clearly visible by red fluorescence (Fig. 4a). Visualization of the BODIPY dye, for both mAbl and $\mathrm{mAb} 2$, showed distinct concentration of the fluorophore in the presence of aggregates (Fig. 4b) but not in the presence of monomer (Fig. 4c) or absence of mAbs (rmHSP70BODIPY alone control, Fig. 4d). It should be noted that $\mathrm{mAb} 1$ was used in a more diluted form than mAb2 in order to achieve optimal conditions for imaging, leading to the lower frequency of BODIPY-labelled rmHSP70-mAbl aggregates observed in Fig. 4b. We infer that BODIPY-rmHSP70 bound to mAb aggregates, forming clumps which could be more readily visualized than when dispersed in bulk solution. These observations are therefore also consistent with specific adhesion of rmHSP70 to aggregates of mAbl and mAb2.

\section{Effect of rmHSP70 on Immune Responses to mAb I and $\mathrm{mAb2}$ in BALB/c Model}

In vivo approaches have been usefully adopted to compare immune responses elicited by aggregated proteins and their

mAb1
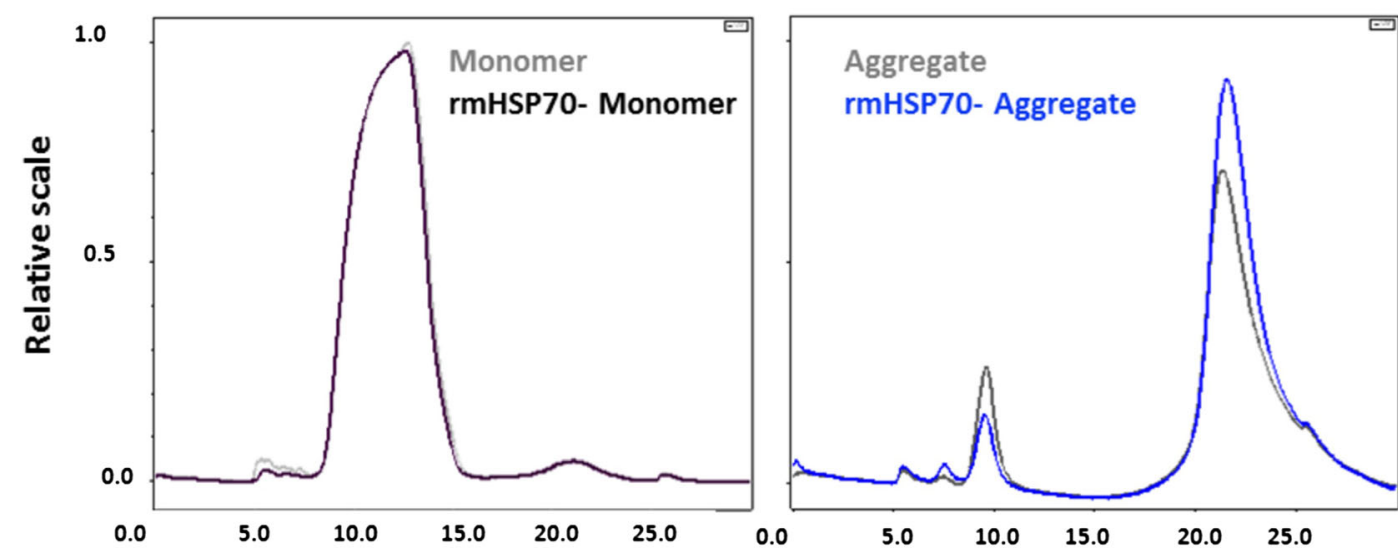

mAb2

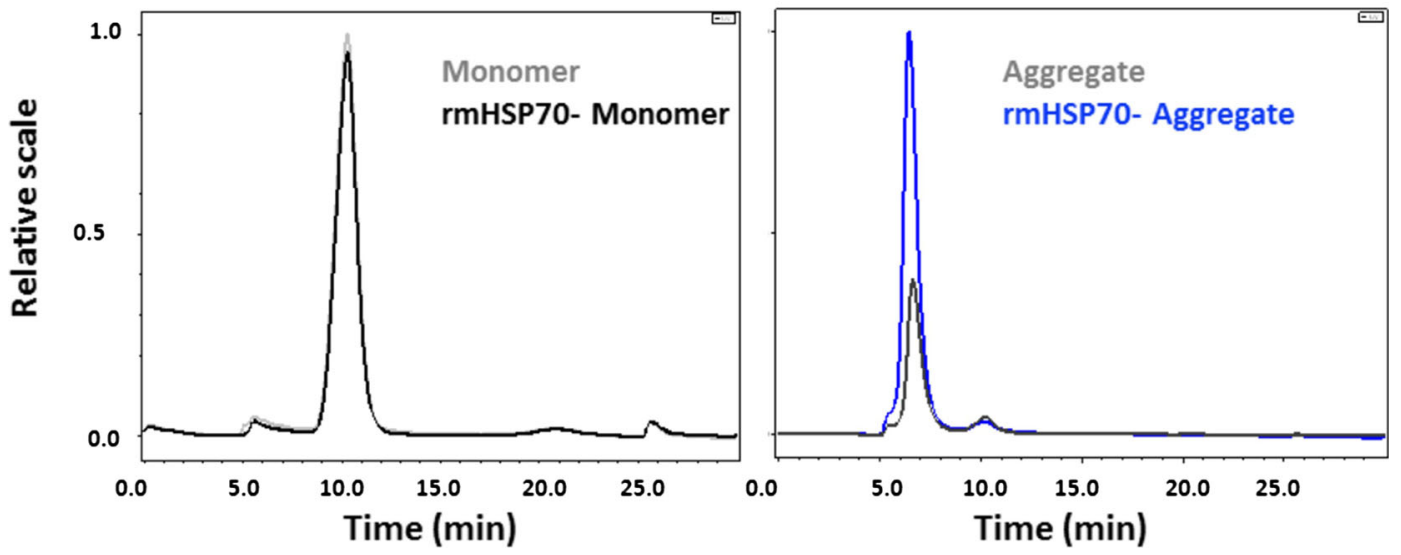

Fig. 3 Assessment of $\mathbf{r m H S P 7 0}$ binding to aggregated $\mathbf{m A b}$ using $\mathbf{A F}^{\mathbf{4}}$. rmHSP70 was added to the aggregated mAbs immediately after aggregation and binding was assessed by $\mathrm{AF}^{4}$. Chromatograms for $\mathrm{mAb} I$ and $\mathrm{mAb} 2$ monomer (with and without $\mathrm{rmHSP70}$ ) and aggregates (with and without rmHSP70) are overlaid as shown. The peak profiles were used to compile the data summarized in Table I (representative data from a single experiment). 
Table I Asymmetric Flow Field Flow Fractionation $\left(\mathrm{AF}^{4}\right)^{1}$

\begin{tabular}{lllll}
\hline$\#$ & $\#$ & Height $^{2}$ & Area & Elution time (min) \\
\hline mAbl & Monomer & 5 & 368.2 & 9.7 \\
& rmHSP70-Monomer & 4.9 & 347.8 & 9.7 \\
& Aggregate & 6 & 1152.8 & 21.2 \\
& rmHSP70-aggregate & 7.7 & 1413.6 & 21.5 \\
mAb2 & Monomer & 4.4 & 288.3 & 10.3 \\
& rmHSP70-Monomer & 4.2 & 281.3 & 10.3 \\
& Aggregate & 4.4 & 217.8 & 6.7 \\
& rmHSP70-aggregate & 21 & 864.4 & 6.5 \\
\hline
\end{tabular}

monomeric counterparts. A common approach is to measure antibody responses provoked in mice by immunizations with the monomeric or aggregated protein $[33,34]$. A BALB/c mouse model was therefore used in the current study to assess the immune responses generated following intraperitoneal (I.P.) immunization with monomer, rmHSP70-monomer, aggregated or rmHSP70-aggregated human mAbs [27].

$\mathrm{mAbl}(250 \mu \mathrm{g})$ was administered as monomer or aggregate, both in the presence or absence of rmHSP70. Naïve mice or PBS only immunization was used as a sham control. Mice were boosted twice at 7 day intervals and were euthanized on day 21. Figure 5 a shows the serum antimAb1 IgM, IgG and selected subclasses (IgG1, IgG2a) antibody responses following administration of thermal and shaking stress-induced aggregates. Levels of anti-mAbl IgG antibody were elevated in the mice immunized with aggregate from thermal-stress and rmHSP70-aggregate mAbl immunized mice, compared to those immunized with monomer mAbl, rmHSP70-monomer mAbl or the PBS immunized control group (Fig. 5a). Similar patterns were recorded with anti-mAb1 IgG1 antibody responses but, due to the sensitivity of the anti-IgGl detection antibody, these achieved considerably higher titres than those obtained for total $\mathrm{IgG}$. Importantly, aggregation of mAblenhanced the IgG2a antibody response compared to monomer and addition of rmHSP70 further enhanced IgG2a for the aggregate but not the monomeric species. These observations are indicative of a Th1-type skewing of the immune responses and consistent with those observed previously for an antibody fragment scFv [27]. The ability of mAbl aggregates generated using shaking stress $(1 \mu \mathrm{m})$ to induce immune responses in the BALB/c model was also examined. A very similar pattern was observed to the thermal stressed aggregates, with aggregate enhancing IgG and IgG1 antibody production and with rmHSP70 addition having a more profound effect on a SYPRO ${ }^{(\mathrm{R})}$ Red- Aggregate
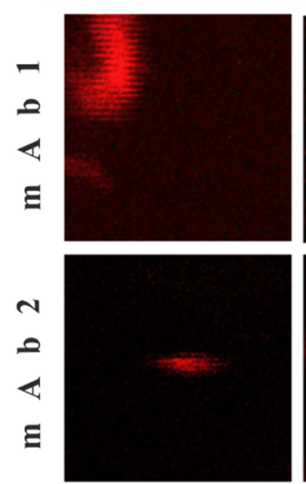

C rmHSP70-BODIPY- Monomer control
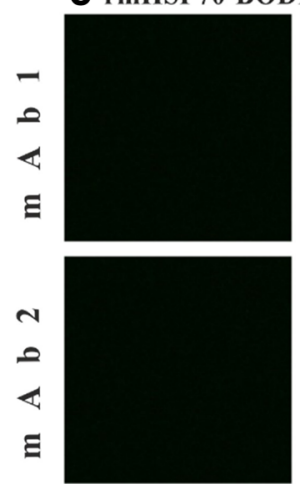
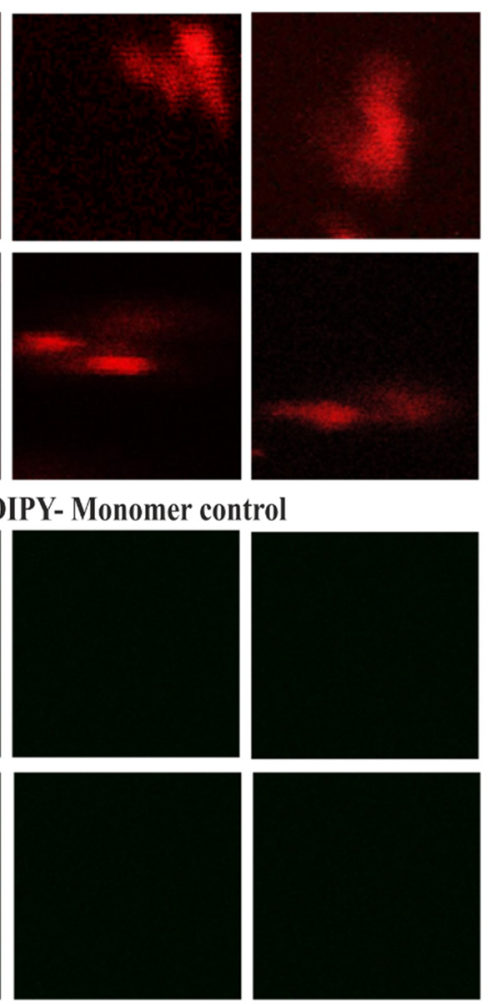

b rmHSP70-BODIPY- Aggregate
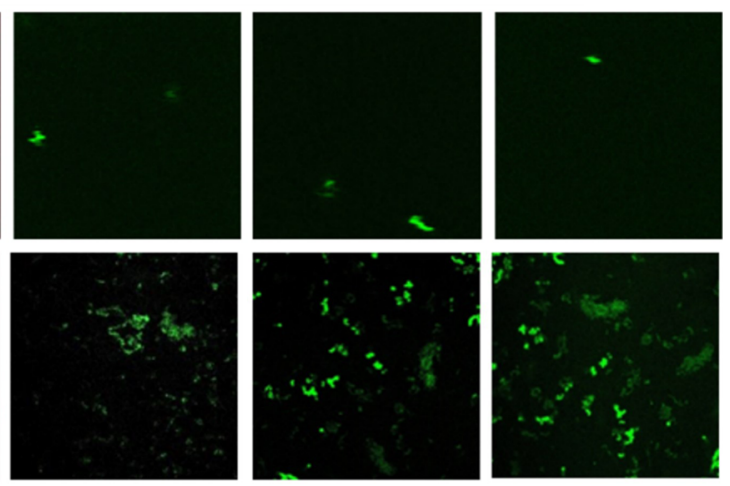

d rmHSP70-BODIPY alone control
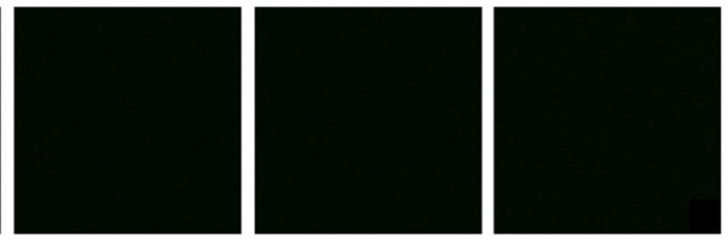

Fig. 4 Assessment of rmHSP70 binding to aggregated mAb using fluorescence imaging by RICS. (a) SYPRO $®$ Red dye stained aggregated samples of mAbI and mAb2. (b) BODIPY FL tagged rmHSP70 (green) added to mAbI and mAb2 post aggregation (0. I\% by mass). (c) Monomer mAbs with rmHSP70-BODIPY FL. (d) rmHSP70-BODIPY FL alone. Data were obtained from a typical experiment using RICS mode and a 40x water immersion objective with slow scanning (pixel size $40 \mathrm{~nm}$ and scanning speed 6.4 microseconds per pixel. 
a

\section{IgG}

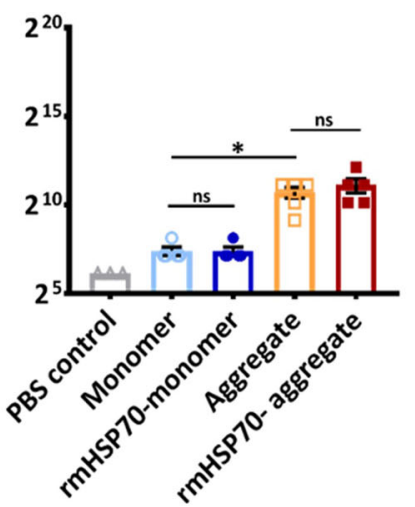

b

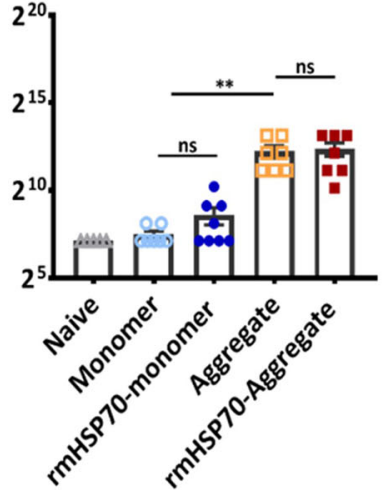

C

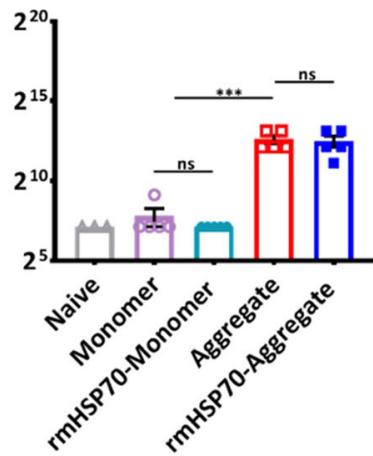

IgG1
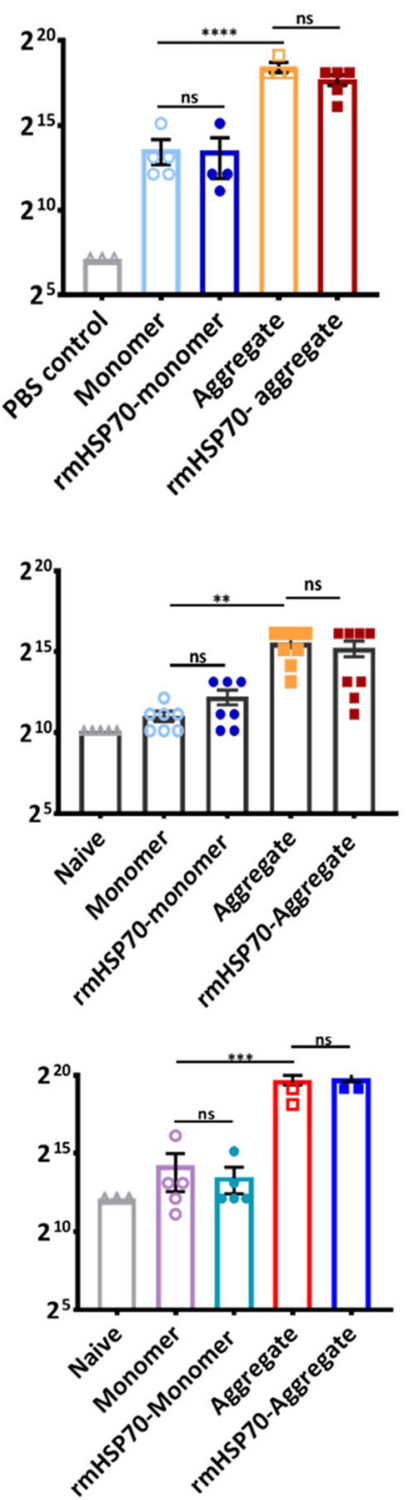

IgG2a
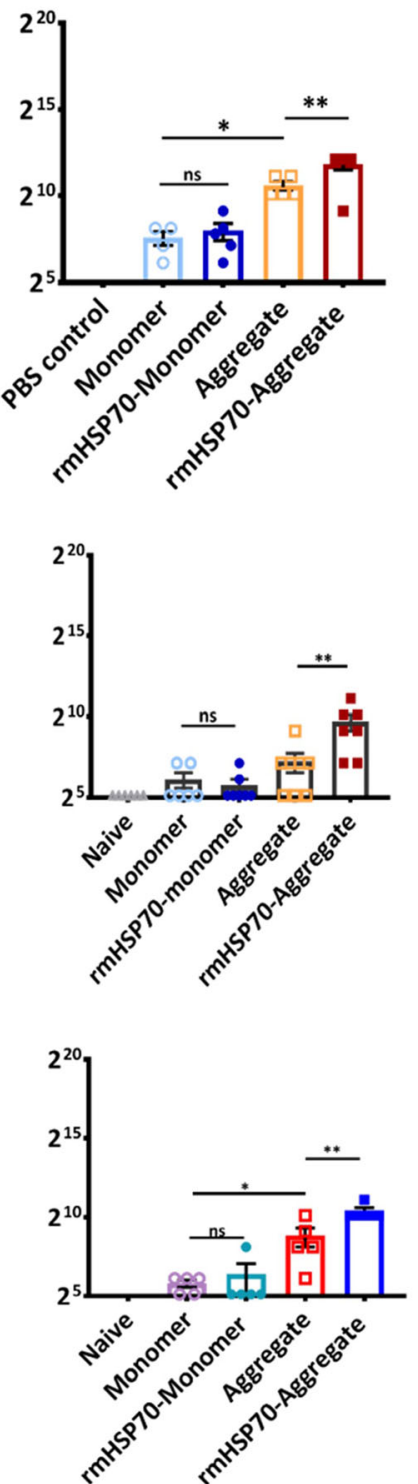

IgM
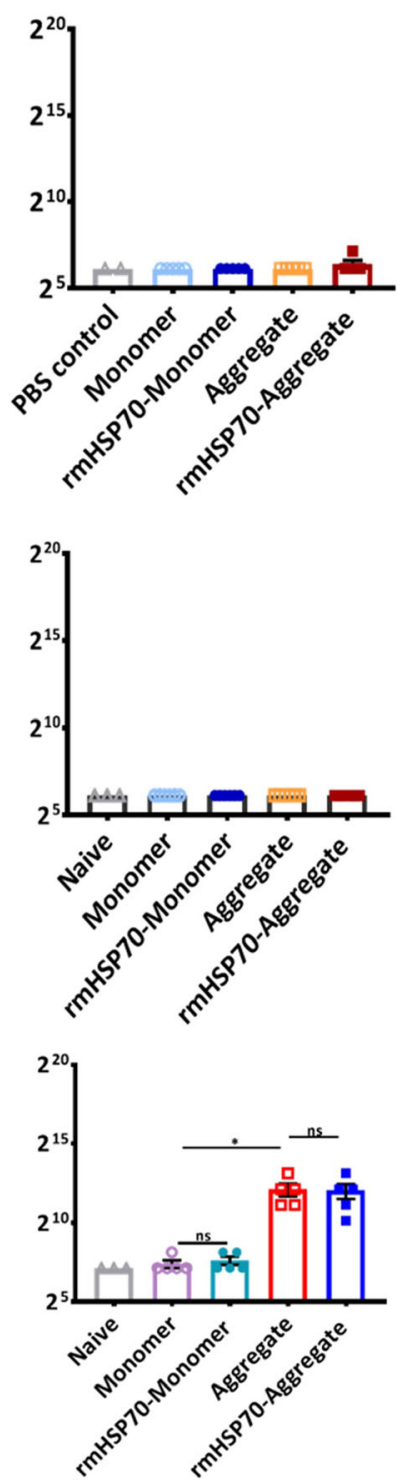

Fig. 5 Antibody responses to aggregated mAbs. (a) mAbl thermal stress-induced aggregates (b) mAbl shaking stress-induced aggregates (c) mAb2 shaking stress-induced aggregates. BALB/C mice received monomer or aggregated protein injections (I.P.) with or without rmHSP70 addition. Mice received booster injections on day 7 and day 14, and were euthanized on day 21 . Doubling dilutions (in 1\% BSA/PBS) of serum samples from monomer, aggregateimmunized animals, PBS immunized or naïve negative control serum samples were analyzed against monomer-coated plates by ELISA for lgG, lgG I, lgG2a and IgM. Data are representative of two independent experiments for mAbI $(n=8)$, and $\mathrm{mAb} 2(n=5)$. ELISA titres for negative control mice (naïve or PBS) were invariably lower than the protein immunization groups $(p<00 \mathrm{I})$, symbols not shown. Differences in antibody serum titres between all sera groups against each substrate were analysed using one way ANOVA ( ${ }^{2} p<0.05$, ** $p<0.0$ I, **** $p<0.00$ I).

enhancing IgG2a antibody production than did aggregation alone (Fig. 5b). There was no detectable anti-mAbl-induced IgM antibody in response to mAbl immunization (Fig. 5a, b).

In order to investigate whether these observations were particular to $\mathrm{mAb} 1, \mathrm{mAb} 2$ was investigated in a similar manner. Preliminary studies performed using $\mathrm{mAb} 2$ indicated that lower doses were needed to obtain measurable serum antibody responses in immunized mice (data not shown), and a dose of $150 \mu \mathrm{g} \mathrm{mAb2}$ was used for the ensuing experiments.
Mice immunized with shaking stress-induced mAb2 aggregates demonstrated increased IgG, IgG1, and IgG2a responses compared to immunization with monomer (Fig. 5c) and, as recorded for $\mathrm{mAbl}$, rmHSP70 further enhanced IgG2a antibody production. A specific anti-mAb2 IgM antibody response was recorded for aggregate-treated mice, but not monomer. Similar patterns of antibody responses were observed in ELISAs for both monomer and aggregate-coated plates of $\mathrm{mAb} 1$ and $\mathrm{mAb} 2$. 
In order to further characterize adaptive immune responses induced in response to $\mathrm{mAb}$ immunization, splenocyte proliferation assays were conducted. Spleens were harvested on day 21 post-immunization and cultured ex vivo with addition of $\mathrm{mAb} 1$ or $\mathrm{mAb} 2$, with or without rmHSP70. The splenocytes were co-cultured with dendritic cells (DCs) from naïve $\mathrm{BALB} / \mathrm{c}$ mice and $\mathrm{mAbl}$ or $\mathrm{mAb} 2$; proliferation was measured with $\left[{ }^{3} \mathrm{H}\right]$-thymidine incorporation. Statistically significant increases in proliferation were observed in the groups of mice that were immunized with rmHSP70aggregate protein compared to $\mathrm{mAbl}$ or mAb2 aggregate alone (Fig. 6a). IFN $\gamma$ secretion ELISpot assays were performed by co-culturing in vitro protein-stimulated splenocytes with protein pulsed-DCs. For mAbl (both thermal and shaking stress induced aggregates), a significantly higher frequency of IFN $\gamma$ secreting splenocytes was observed in the group of mice immunized with rmHSP70-aggregate compared with aggregate alone. For mAb2, however, we did not observe any effect of rmHSP70 addition (Fig. 6b). Nevertheless, the cellular responses obtained were generally consistent with the antibody measurements, indicative of a Thl enhancement in the groups immunized with aggregated mAbs, and provided further evidence for a stimulatory effect of rmHSP70 on immune responses to aggregated mAbs.

\section{DISCUSSION}

Protein aggregation can be described as the self-association of monomers in their native or partially unfolded forms $[35,36]$, and is a common phenomenon observed in biopharmaceutical preparations. There is evidence that aggregates can stimulate an anti-drug immune response which may impair drug efficacy. However, the mechanisms through which immunogenicity is enhanced or conferred on proteins are only poorly understood [37]. Recently we reported that IgG2a antibody responses to an aggregated model $\mathrm{scFv}$ were stimulated in a mouse model by addition of a low $(0.1 \%)$ level of a bacterial HSP, DnaK [27]. This observation led us to investigate whether this effect was also observed with human mAbs and a murine HSP. Aggregates that may be present in protein products can range from dimers to subvisible or visible particles. They can be formed during different stages of production, transport or delivery to the patient, in response to diverse stresses [35,38] Aggregates formed in biotherapeutic monoclonal antibodies under the influence of various stresses have been characterized by various techniques on the basis of their sizes, ranging from $\mathrm{nm}$ to micron dimensions [39-42]. The $\mathrm{mAb}$ aggregates employed in this study fall within this range and can therefore be regarded as typical, at least in terms of size, compared with those studied previously.

It is well established that HSP family members recognize exposed hydrophobic residues of misfolded or denatured proteins which are retained for ubiquitination and subsequent targeting to the proteasome for degradation [20,43]. Using co-sedimentation and western blotting, we have shown that rmHSP70 bound to aggregates of both mAbs. Similar phenomena were observed when aggregates were analyzed using $\mathrm{AF}^{4}$ where the presence of rmHSP70 had an effect on the migration profile of each mAb. Supporting these observations, microscopy demonstrated that fluorescently labelled rmHSP70 bound to the aggregated mAbs. Although the level of rmHSP70 used in these studies is high by industry standards (1:1000), our results provide evidence that HSP70 impurities can be selectively accumulated by adhesion to aggregates. This opens up the possibility that HSPs in general can selectively accumulate by adhesion to aggregated material, even though the overall levels of HSPs are low.

Our observations on IgG subclass specificity are consistent with those made previously by Ratanji et al. [27], which showed a stimulation of IgG2a levels characteristic of Th1skewing of the immune response (Fig. 5). Interestingly, no increases in IgM antibody levels above PBS controls were detected for the immunizations of mAbl. This observation could be due to the immunogenic potential of mAbl, the serum $\operatorname{IgM}$ repertoire and the lifespan of $\operatorname{IgM}$ in the in vivo system [44]. Additional evidence for the stimulatory effects of rmHSP70 was obtained from cellular proliferation assays, using splenocytes cultured with antigen-primed DCs. Splenocyte proliferation was elevated in the group of mice immunized with rmHSP70-aggregated protein, compared with those immunized with aggregate alone, demonstrating an enhanced CD4-mediated T cell response. Stimulation of IFN $\gamma$ secretion was particularly pronounced for mAbl aggregates in splenocytes from the mice which received rmHSP70aggregate, compared with aggregate alone. We think that the enhancement of mAb immunogenicity by rmHSP70 which we observe is unlikely to be attributable to its immunogenicity, for several reasons. First, the levels of rmHSP70 used were very low $(0.1 \%$ of total protein inoculated). It is remarkable that such a low level of impurity can drive significant responses to IgG2a (Fig. 5) and splenocyte proliferation (Fig. 6a). Second, the Cricetulus griseus (Chinese Hamster) HSP70 is 98\% identical to the mouse HSP70 sequence. Third, we do not observe an enhancement of IgG2a levels for monomer compared with rmHSP70-monomer, only for aggregate compared with rmHSP70-aggregate (Fig. 5).

Previous studies using mouse models have shown that HSP70 can be used as an adjuvant in cancer vaccine development strategies $[45,46]$. HSPs have therefore been harnessed as adjuvants of vaccines against cancers and infectious diseases [47]: examples include Phase I clinical trials for Glioblastoma (HSP70), colon carcinoma, Phase I-II studies for Non-small cell lung carcinoma (HSP70-activated NK cells) and a Phase I HIV vaccine study [25]. The adjuvantlike activity of HSP70 has been demonstrated in vitro by 
a $\mathrm{mAb} 1$

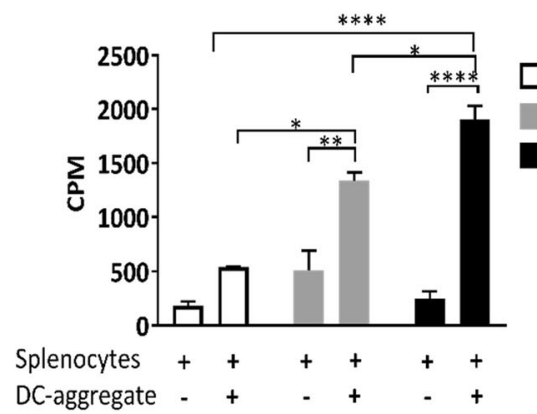

$\mathrm{mAb2}$

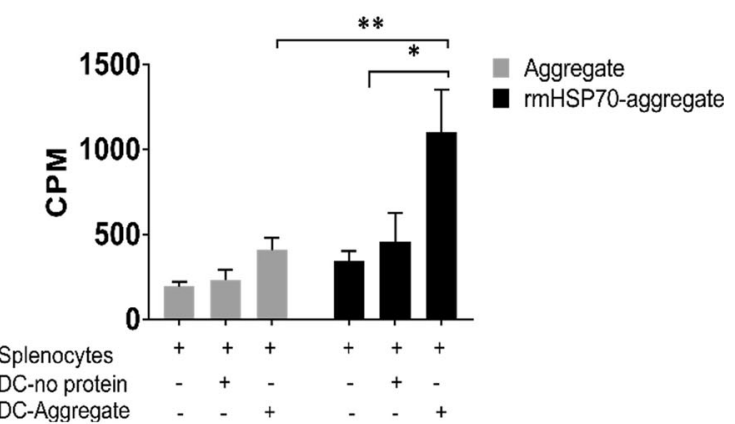

b

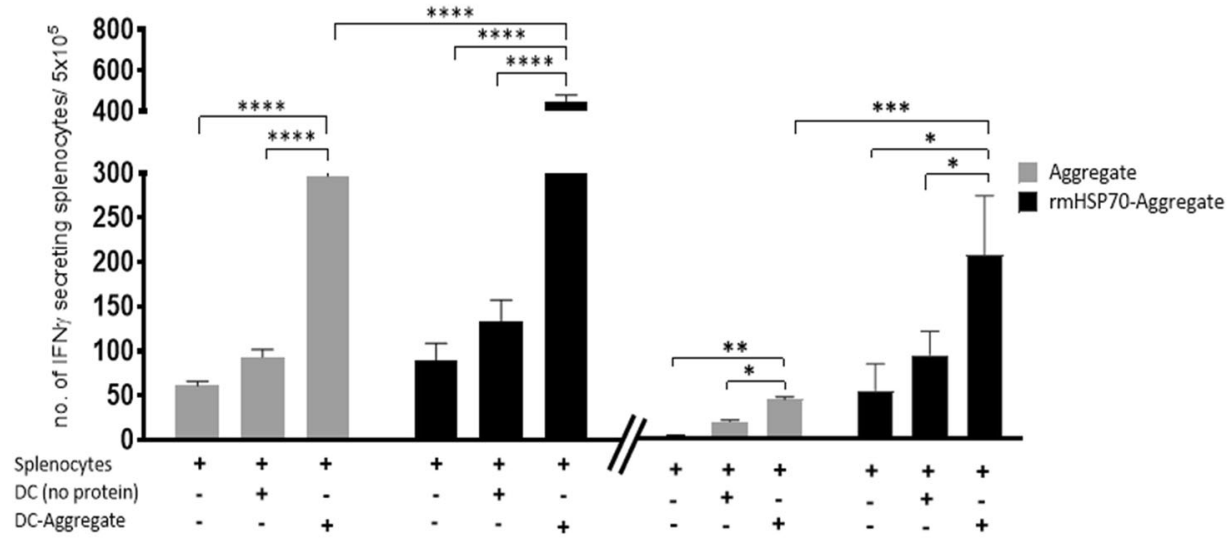

mAb1 (thermal stress) mAb1 (shaking stress)

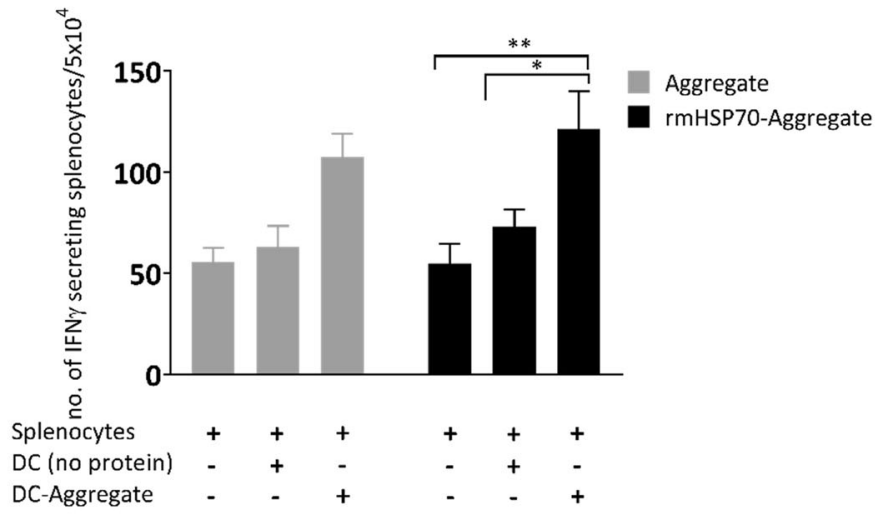

\section{mAb2 (shaking stress)}

Fig. 6 Assessment of cellular responses in BALB/c mice immunized with aggregated mAbs in the presence or absence of rmHSP70. (a) $\left[{ }^{3} \mathrm{H}\right]$ thymidine incorporation proliferation assay for aggregated $\mathrm{mAb} I$ (thermal stress) and mAb2 (shaking stress). Splenocytes were isolated from immunized mice and stimulated ex vivo with protein. $\left[{ }^{3} \mathrm{H}\right]$ thymidine incorporation proliferation assays were performed by co-culturing in vitro protein-stimulated splenocytes from immunized mice with protein-pulsed DCs. A PBS only immunization was used as sham control. (b) IFNy ELISpot assays. The IFNy ELISpot assay was performed under the same culture conditions as (A) to assess IFNy secretion in response to co-culture. The experiments were performed on two separate occasions, $\mathrm{n}=8$, (for thermal and shaking stress aggregates from $\mathrm{mAbl}$ ) and $n=5$ for $\mathrm{mAb2}$. Comparisons of the means $( \pm \mathrm{SEM})$ between groups are made. Statistical significance of the results obtained was calculated using one way ANOVA. ${ }^{*} p<0.05$, ** $p<0.01$, **** $p<0.001$.

coupling to superparamagnetic iron oxide nanoparticles (SPIONs) to form HSP70-SPION conjugates. HSP70SPIONs have shown effective delivery of immunogenic peptides from tumor lysates to DCs, stimulating a tumor-specific, CD8+ cytotoxic T cell response in experimental glioma models [48]. It is also known that HSP-peptide complexes can 
act as typical tumor-specific foreign antigens, chaperokines and adjuvants that facilitate uptake, processing, and presentation for tumor-specific antigens which are cross-presented by APGs to T lymphocytes [49]. The influence of HSPs on the induction of immunogenicity therefore appears to be a general phenomenon, rather than being confined to specific HSPimmunogen pairs.

HSP70 is released from cells in response to stress conditions [50]; more generally, intracellular proteins will be released by damaged, necrotic cells in a passive manner [51]. It is therefore not surprising that HSP family members have been recorded as HCP impurities in purified mAbs [15,52]. HSP70 is listed as a persistent HCP impurity in $29 \mathrm{mAb}$ preparations following cross-interaction or Protein A affinity chromatography [53]. Accepted limits of HCP impurities are generally between 1 and 100 ppm [54]; ostensibly this would appear to be a low level but it does not take account of selective adsorption to aggregates, which would increase the apparent local concentration. Doses of therapeutic mAbs are well above $100 \mathrm{mg}[55,56]$, so an impurity level of $0.1 \%$ of a particular $\mathrm{HCP}$ would result in administration of $100 \mu \mathrm{g}$, a level which could influence immunogenic responses to aggregates.

It has been reported that HSPs interact with and activate the immune system via Toll-like receptors on antigenpresenting cells $[57,58]$. It is also possible that aggregation itself enhances antigen uptake, and the presence of DnaK within the complex somehow enhances processing and presentation once inside the antigen-presenting cell. It is interesting to note that elevated levels of HSPs have been reported in the plasma of patients with certain illnesses such as dyslipidaemia [59], prostate cancer [60], and neurodegenerative diseases [61].

\section{CONCLUSION}

These observations confirm and extend our previous work on DnaK/scFv [27], and provide additional evidence that the adjuvant-like effects of HSPs are general, rather than specific, to particular HSP/immunogen pairs. The precise mechanism(s) for the adjuvant effects of HSPs are currently a matter of debate, however. It is therefore difficult to predict which HSPs, or indeed other categories of HCPs, might act in this way and, if so, at what levels. Here we have used HSP70 as an exemplar HCP but our observations open up the possibility that a complex mixture of multiple HCPs may have synergistic effects on the immunogenicity of biotherapeutic mAbs. The implications for the immunogenicity of therapeutic mAbs in humans are harder to discern. We would argue that further work is needed to investigate the nature of this effect and determine the extent to which it contributes to the immunogenicity of aggregates of biopharmaceutical drugs.

\section{ACKNOWLEDGMENTS AND DISCLOSURES}

We thank Lorna Beresford for her valuable support with animal work and Angela Thistlethwaite for her help with gel electrophoresis. We would also like to thank the Faculty Biomolecular Core Facility for DLS for instrument support and expertise. S. Rane was employed on a grant from MedImmune to carry out this research project. J. Derrick and the University of Manchester have received research grants from MedImmune. The other authors declare that they have no other relevant conflicts of interest.

Funding Details. This work was funded by MedImmune.

Open Access This article is distributed under the terms of the Creative Commons Attribution 4.0 International License (http://creativecommons.org/licenses/by/4.0/), which permits unrestricted use, distribution, and reproduction in any medium, provided you give appropriate credit to the original author(s) and the source, provide a link to the Creative Commons license, and indicate if changes were made.

Publisher's Note Springer Nature remains neutral with regard to jurisdictional claims in published maps and institutional affiliations.

\section{REFERENCES}

1. Li J, Zhu Z. Research and development of next generation of antibody-based therapeutics. Acta Pharmacol Sin. 2010;31:1198207.

2. Geng X, Kong X, Hu H, Chen J, Yang F, Liang H, et al. Research and development of therapeutic mAbs: an analysis based on pipeline projects. Hum Vacc Immunother. 2015;11:2769-76.

3. Li J, Yang C, Xia Y, Bertino A, Glaspy J, Roberts M, et al. Thrombocytopenia caused by the development of antibodies to thrombopoietin. Blood. 2001;98:3241-8.

4. Pendley C, Schantz A, Wagner C. Immunogenicity of therapeutic monoclonal antibodies. Curr Opin Mol Ther. 2003;5:172-9.

5. Tabrizi MA, Roskos LK. Preclinical and clinical safety of monoclonal antibodies. Drug Discov Today. 2007;12:540-7.

6. Carpenter JF, Randolph TW, Jiskoot W, Grommelin DJA, Middaugh GR, Winter G, et al. Overlooking subvisible particles in therapeutic protein products: gaps that may compromise product quality. J Pharm Sci. 2009;98:1201-5.

7. den Engelsman J, Garidel P, Smulders R, Koll H, Smith B, Bassarab $\mathrm{S}$, et al. Strategies for the assessment of protein aggregates in pharmaceutical biotech product development. Pharm Res. 2011;28:920-33.

8. Singh SK. Impact of product-related factors on immunogenicity of biotherapeutics. J Pharm Sci. 2011;100:354-87.

9. Van Beers MMC, Sauerborn M, Gilli F, Brinks V, Schellekens H, Jiskoot W. Aggregated recombinant human interferon beta induces antibodies but no memory in immune-tolerant transgenic mice. Pharm Res. 2010;27:1812-24. 
10. Cromwell MEM, Hilario E, Jacobson F. Protein aggregation and bioprocessing. AAPS J. 2006;8:E572-9.

11. Braun A, Kwee L, Labow MA, Alsenz J. Protein aggregates seem to play a key role among the parameters influencing the antigenicity of interferon alpha (IFN-alpha) in normal and transgenic mice. Pharm Res. 1997;14:1472-8.

12. Ryff JC, Schellekens H. Immunogenicity of rDNA-derived pharmaceuticals. Trends Pharmacol Sci. 2002;23:254-6.

13. Schellekens H. Bioequivalence and the immunogenicity of biopharmaceuticals. Nat Rev Drug Discov. 2002;1:457-62.

14. Ratanji KD, Dearman RJ, Kimber I, Thorpe R, Wadhwa M, Derrick JP. Subvisible aggregates of immunogenic proteins promote a Th1-type response. Toxicol Sci. 2016;153:258-70.

15. Levy NE, Valente KN, Choe LH, Lee KH, Lenhoff AM. Identification and characterization of host cell protein productassociated impurities in monoclonal antibody bioprocessing. Biotechnol Bioeng. 2014;111:904-12.

16. Wadhwa M, Skog AL, Bird C, Ragnhammar P, Lilljefors M, Gaines-Das R, et al. Immunogenicity of granulocyte-macrophage colony-stimulating factor (GM-CSF) products in patients undergoing combination therapy with GM-CSF. Clin Cancer Res. 1999;5: 1353-61.

17. Schenauer MR, Flynn GC, Goetze AM. Profiling the effects of process changes on residual host cell proteins in biotherapeutics by mass spectrometry. Biotechnol Prog. 2013;29:951-7.

18. Gao SX, Zhang Y, Stansberry-Perkins K, Buko A, Bai SJ, Nguyen $\mathrm{V}$, et al. Fragmentation of a highly purified monoclonal antibody attributed to residual CHO cell protease activity. Biotechnol Bioeng. 2011;108:977-82.

19. Walker DE, Yang F, Carver J, Joe K, Michels DA, Yu XC. A modular and adaptive mass spectrometry-based platform for support of bioprocess development toward optimal host cell protein clearance. MAbs. 2017;9:654-63.

20. Fink AL. Chaperone-mediated protein folding. Physiol Rev. 1999;79:425-49.

21. Morris JP, Thatje S, Hauton C. The use of stress-70 proteins in physiology: a re-appraisal. Mol Ecol. 2013;22:1494-502.

22. Ellis RJ, Hartl FU. Principles of protein folding in the cellular environment. Curr Opin Struc Biol. 1999;9:102-10.

23. JiangJ, Xie D, Zhang W, Xiao G, Wen J. Fusion of Hsp70 to mageal enhances the potency of vaccine-specific immune responses. J Transl Med. 2013;11:300.

24. Blachere NE, Li Z, Chandawarkar RY, Suto R, Jaikaria NS, Basu $\mathrm{S}$, et al. Heat shock protein-peptide complexes, reconstituted in vitro, elicit peptide-specific cytotoxic T lymphocyte response and tumor immunity. J Exp Med. 1997;186:1315-22.

25. Shevtsov M, Multhoff G. Heat shock protein-peptide and HSPbased immunotherapies for the treatment of cancer. Front Immunol. 2016;7:171

26. Junqueira-Kipnis AP, Marques Neto LM, Kipnis A. Role of fused mycobacterium tuberculosis immunogens and adjuvants in modern tuberculosis vaccines. Front Immunol. 2014;5:188.

27. Ratanji KD, Derrick JP, Kimber I, Thorpe R, Wadhwa M, Dearman RJ. Influence of Escherichia coli chaperone DnaK on protein immunogenicity. Immunology. 2017;150:343-55.

28. Hamrang Z, Hussain M, Tingey K, Tracka M, Casas-Finet JR, Uddin S, et al. Characterisation of stress-induced aggregate size distributions and morphological changes of a bi-specific antibody using orthogonal techniques. J Pharm Sci. 2015; 104:2473-81.

29. Gokhale NA, Abraham A, Digman MA, Gratton E, Cho W. Phosphoinositide specificity of and mechanism of lipid domain formation by annexin A2-p1 1 heterotetramer. J Biol Chem. 2005;280: 42831-40.

30. Wagner M, Holzschuh S, Traeger A, Fahr A, Schubert US. Asymmetric flow field-flow fractionation in the field of nanomedicine. Anal Chem. 2014;86:5201-10.
31. Saif JMS, Vadakekolathu J, Rane SS, Mcdonald D, Ahmad M, Mathieu M, et al. Novel prostate acid phosphatase-based peptide vaccination strategy induces antigen-specific $\mathrm{T}$-cell responses and limits tumour growth in mice. Eur J Immunol. 2014;44:994-1004.

32. Pere H, Montier Y, Bayry J, Quintin-Colonna F, Merillon N, Dransart E, et al. ACCR4 antagonist combined with vaccines induces antigen-specific CD8+T cells and tumor immunity against self antigens. Blood. 201 1;1 18:4853-62.

33. Freitag AJ, Shomali M, Michalakis S, Biel M, Siedler M, Kaymakcalan Z, et al. Investigation of the immunogenicity of different types of aggregates of a murine monoclonal antibody in mice. Pharm Res. 2015;32:430-44.

34. Shomali M, Freitag A, Engert J, Siedler M, Kaymakcalan Z, Winter G, et al. Antibody responses in mice to particles formed from adsorption of a murine monoclonal antibody onto glass microparticles. J Pharm Sci. 2014;103:78-89.

35. Chi EY, Krishnan S, Randolph TW, Carpenter JF. Physical stability of proteins in aqueous solution: mechanism and driving forces in nonnative protein aggregation. Pharm Res. 2003;20:1325-36.

36. Roberts CJ. Non-native protein aggregation kinetics. Biotechnol Bioeng. 2007;98:927-38.

37. Ratanji KD, Derrick JP, Dearman RJ, Kimber I. Immunogenicity of therapeutic proteins: influence of aggregation. J Immunotoxicol. 2014;11:99-109.

38. Mahler HC, Friess W, Grauschopf U, Kiese S. Protein aggregation: pathways, induction factors and analysis. J Pharm Sci. 2009;98: 2909-34.

39. Filipe V, Hawe A, Jiskoot W. Critical evaluation of nanoparticle tracking analysis (NTA) by NanoSight for the measurement of nanoparticles and protein aggregates. Pharm Res. 2010;27:796810 .

40. Joubert MK, Luo Q Nashed-Samuel Y, Wypych J, Narhi LO. Classification and characterization of therapeutic antibody aggregates. J Biol Chem. 2011;286:25118-33.

41. Morefield GL, Sokolovska A, Jiang D, Hogenesch H, Robinson JP, Hem SL. Role of aluminum-containing adjuvants in antigen internalization by dendritic cells in vitro. Vaccine. 2005;23:1588-95.

42. Fifis T, Gamvrellis A, Crimeen-Irwin B, Pietersz GA, LiJ, Mottram PL, et al. Size-dependent immunogenicity: therapeutic and protective properties of Nano-vaccines against tumors. J Immunol. 2004; 173:3148-54.

43. Stetler RA, Gan Y, Zhang W, Liou AK, Gao Y, Cao G, et al. Heat shock proteins: cellular and molecular mechanisms in the central nervous system. Prog Neurobiol. 2010;173:184-211.

44. Haury M, Sundblad A, Grandien A, Barreau C, Coutinho A, Nobrega A. The repertoire of serum IgM in normal mice is largely independent of external antigenic contact. Eur J Immunol. 1997;27:1557-63.

45. LiJ, Xing Y, Zhou Z, Yao W, Cao R, Li T, et al. Microbial HSP70 peptide epitope 407-426 as adjuvant in tumor-derived autophagosome vaccine therapy of mouse lung cancer. Tumour Biol. 2016;37:15097-105.

46. Lu Y, Ouyang K, Fang J, Zhang H, Wu G, Ma Y, et al. Improved efficacy of DNA vaccination against prostate carcinoma by boosting with recombinant protein vaccine and by introduction of a novel adjuvant epitope. Vaccine. 2009;27:541 1-8.

47. Segal BH, Wang X-Y, Dennis CG, Youn R, E A R, Manjili MH, et al. Heat shock proteins as vaccine adjuvants in infections and cancer. Drug Discov Today. 2006;11:534-40.

48. Shevtsov MA, Nikolaev BP, Ryzhov VA, Yakovleva LY, Dobrodumov AV, Marchenko YY, et al. Brain tumor magnetic targeting and biodistribution of superparamagnetic iron oxide nanoparticles linked with 70-kDa heat shock protein study by nonlinear longitudinal response. J Magn Magn Mater. 2015;388:12334. 
49. Noessner E, Gastpar R, Milani V, Brandl A, Hutzler PJS, Kuppner $\mathrm{MC}$, et al. Tumor-derived heat shock protein 70 peptide complexes are cross-presented by human dendritic cells. J Immunol. 2002;169: 5424-32.

50. Broquet AH, Thomas G, Masliah J, Trugnan G, Bachelet M. Expression of the molecular chaperone Hsp70 in detergentresistant microdomains correlates with its membrane delivery and release. J Biol Chem. 2003;278:21601-6.

51. Saito K, Dai Y, Ohtsuka K. Enhanced expression of heat shock proteins in gradually dying cells and their release from necrotically dead cells. Exp Cell Res. 2005;310:229-36.

52. Zhang Q Goetze AM, Cui H, Wylie J, Trimble S, Hewig A, et al. Comprehensive tracking of host cell proteins during monoclonal antibody purifications using mass spectrometry. MAbs. 2014;6: 659-70.

53. Valente KN, Levy NE, Lee KH, Lenhoff AM. Applications of proteomic methods for $\mathrm{CHO}$ host cell protein characterization in biopharmaceutical manufacturing. Curr Opin Biotechnol. 2018;53:144-50.

54. Doneanu CE, Xenopoulos A, Fadgen K, Murphy J, Skilton SJ, Prentice $\mathrm{H}$, et al. Analysis of host-cell proteins in biotherapeutic proteins by comprehensive online two-dimensional liquid chromatography/mass spectrometry. MAbs. 2012;4:24-44.

55. Levêque D, Wisniewski S, Jehl F. Pharmacokinetics of therapeutic monoclonal antibodies used in oncology. Anticancer Res. 2005;25: 2327-43.
56. Castro M, Wenzel SE, Bleecker ER, Pizzichini E, Kuna P, Busse WW, et al. Benralizumab, an anti-interleukin 5 receptor $\alpha$ monoclonal antibody, versus placebo for uncontrolled eosinophilic asthma: a phase $2 \mathrm{~b}$ randomised dose-ranging study. Lancet Resp Med. 2014;2:878-90.

57. Enomoto Y, Bharti A, Khaleque AA, Song B, Liu C, Apostolopoulos V, et al. Enhanced immunogenicity of heat shock protein 70 peptide complexes from dendritic cell-tumor fusion cells. J Immunol. 2006; 177:5946-55.

58. Mukai T, Maeda Y, Tamura T, Matsuoka M, Tsukamoto Y, Makino M. Induction of cross-priming of naive CD8+ T lymphocytes by recombinant bacillus Calmette-Guerin that secretes heat shock protein 70 -major membrane protein-II fusion protein. J Immunol. 2009;183:6561-8.

59. Calderwood SK. Heat shock proteins in extracellular signaling. Methods. 2007;43:167.

60. Ghayour-Mobarhan M, Lamb DJ, Lovell DP, Livingstone C, Wang T, Ferns GAA. Plasma antibody titres to heat shock proteins-60, -65 and -70 : their relationship to coronary risk factors in dyslipidaemic patients and healthy individuals. Scand J Clin Lab Inv. 2005;65:601-13.

61. Zhang X, Xu Z, Zhou L, Chen Y, He M, Cheng L, et al. Plasma levels of Hsp70 and anti-Hsp70 antibody predict risk of acute coronary syndrome. Cell Stress Chaperon. 2010;15:675-86. 